\title{
Collective Capacity to Aspire? Aspirations and Livelihood Strategies in the Zambezi Region, Namibia
}

\author{
Mascha Aring ${ }^{1}(0)$ Ole Reichardt ${ }^{2} \cdot$ Ewaldine Menjono Katjizeu $^{3}$. \\ Brendan Luyanda ${ }^{4}$. Carolin Hulke ${ }^{5}$
}

Accepted: 12 May 2021 / Published online: 21 May 2021

(c) The Author(s) 2021

\begin{abstract}
This paper investigates rural development from a micro-level standpoint, focusing on individual and collective aspirations. We aim to deepen understanding of how a person's socio-economic environment shapes their aspirations and simultaneously how aspirations contribute to future-oriented actions. In combining concepts of sustainable livelihoods and aspirations with a context of 'ordinary uncertainties' (Pine, Ordinary uncertainties: remembering the past and imagining the future at times of rupture and mobility. In: Paper presented at the conference "Rurality and FutureMaking. Comparative Perspectives from Europe, the Middle East, and the Mediterranean”, 22-24 May, Cologne, Germany, 2019), we discuss the role of individual and collective aspirations in developing livelihood strategies. Drawing on qualitative data from field research in Namibia's Zambezi region, we identify crucial factors that influence aspirations: multiple uncertainties, experiences, and role models. Access to diverse experiences and social exchange shapes future-oriented aspirations, and therefore needs to be included in rural development strategies that account for diversity within communities.
\end{abstract}

Keywords Namibia $\cdot$ Zambezi region $\cdot$ Aspirations $\cdot$ Livelihoods $\cdot$ Capacity to aspire $\cdot$ Rural development

\section{Résumé}

Cet article étudie le développement rural d'un point de vue microéconomique, en se concentrant sur les aspirations individuelles et collectives. Nous cherchons à comprendre plus en profondeur la manière dont l'environnement socio-économique d'une personne façonne ses aspirations et, dans le même temps, de la manière dont les aspirations contribuent à des actions orientées vers l'avenir. En combinant un contexte d' «incertitudes ordinaires» (Pine, Ordinary uncertainties: remembering the past and imagining the future at times of rupture and mobility. In: Paper presented at the

Mascha Aring

m.aring@posteo.de

Extended author information available on the last page of the article 
conference "Rurality and Future-Making. Comparative Perspectives from Europe, the Middle East, and the Mediterranean", 22-24 May, Cologne, Germany, 2019) avec les concepts de moyens de subsistances durables et d'aspirations, nous discutons du rôle des aspirations individuelles et collectives dans l'élaboration de stratégies pour gagner sa vie. Nous nous appuyons sur des données qualitatives issues d'études sur le terrain dans la région du Zambèze en Namibie pour identifier les facteurs essentiels qui influencent les aspirations : les incertitudes multiples, les expériences et les modèles de comportement. Le fait d'avoir accès à une diversité d'expériences et d'échanges sociaux façonne les aspirations pour le futur et doit donc être inclus dans des stratégies de développement rural qui tiennent compte de la diversité au sein des communautés.

\section{Introduction}

Rural households in Namibia's north-eastern Zambezi region mostly depend on agricultural and livestock production. In a representative household survey conducted in 2014 (Mosimane et al. 2014), 65\% of households cited agriculture as their most important livelihood source. Furthermore, political strategies and the media promote the region as Namibia's future 'food basket', producing food not only for subsistence, but to feed the whole nation. However, the absence of visible value capture in agricultural value chains (Hulke et al. 2020), and the high rate of people who survive on less than US\$ 1.90 per day (absolute poverty rate of $17.6 \%$, World Bank 2020), indicate that most rural households are left out of policies aimed at improving livelihoods. Moreover, the National Development Plan (NDP5) does not include region-specific implementation strategies, but only a national goal of sustainable development. The plan mainly aims at diversifying economic sectors and is built around broad notions of economic progress, social transformation, environmental sustainability, and good governance (Republic of Namibia 2017). Whether such a 'one size fits all' national policy can be effective for the Zambezi region is questionable when adopting a livelihood perspective.

Economic growth has frequently been unable to significantly reduce inequality on the African continent (Mpofu and Ndlovu-Gatsheni 2019 2019; World Bank 2013). Indeed, postcolonial critiques of development studies have led to calls for a paradigm shift away from a Western-centric imperative toward 'modernisation' and economic growth (see e.g., 'modernization theory' by Rostow 1960). Instead,

in order for a meaningful and systematic decolonisation of development studies to take place, there is a need to shift the geography and biography of knowledge and to begin to articulate the experience of development from Africa as a privileged epistemic site capable of formulating its own development trajectory (Ndlovu-Gatsheni 2019, p. 46).

In this article, we focus on 'aspirations' as a conceptual lens that can situate local and personal ideas of the future at the centre of livelihood and development analyses. Sustainable livelihoods, as a core concept of development studies, incorporates 
the issue of personal visions for the future under a rather broad concept of social capital. Therefore, in this article we examine ways that aspirations-as analysed by scholars such as Appadurai (2004) or Ray (2006) — can advance the study of livelihoods in Namibia's Zambezi region.

Aspiration as a scientific concept contributes to discussions of poverty, economic development, and cultural factors that influence futures and economic decision making (Appadurai 2004; Bernard and Taffesse 2014; Ray 2006; Besley 2017; Iqani 2017). The aspirations concept is employed to evaluate 'strategies of the poor' (Dalton et al. 2015; Dorward 2009; Dorward et al. 2009; Ray 2006), to emphasise the claim that concepts of the future are culturally and contextually bounded (Appadurai 2013; Bandak and Janeja 2018), and to address the 'empowerment of the poor' (Appadurai 2004). Consequently, this paper aims to develop a deeper understanding of how aspirations are formed in Zambezi, especially in contexts of profound uncertainties, including the extent to which they determine actual, future-oriented livelihood strategies, both individually and collectively. Following remarks by Ndlovu-Gatsheni (2019), we address whether inquiries into aspirations can provide a localised perspective on images of future.

By investigating these issues, we not only consider individual aspirations, but we also address aspiration as a 'cultural capacity,' or an ability by and of 'the poor' to collectively voice their needs and visions for a future with more favorable social, cultural, and economic circumstances (Appadurai 2004). We integrate our concern for aspirations with Pines' (2019) notion of 'ordinary uncertainties' - a state in which uncertainty is understood as structural feature of society, but with tangible effects on people's everyday lives - to address how aspirations are formed by those living under conditions of poverty.

We chose a micro-level research design to compare people's aspirations through daily practices with actual impacts of different policies. Through our analysis, we derive place-based policy recommendations that address how a better understanding of local aspirations can contribute to people's aims to bring about improved livelihoods.

\section{Theoretical Background}

In this study, the concept of aspirations is used to examine the influence of future visions, including their cultural embeddedness, on livelihood strategies and decisionmaking, especially in contexts of poverty and economic development (Appadurai 2004; Bernard and Taffesse 2014; Besley 2017; Iqani 2017; Lybbert and Wydick 2018; Ray 2006). We bring our concern with aspirations together with a livelihoods approach in development studies, and a concept of uncertainty to account for everyday challenges connected with making a living from no or very little income. We suggest that a concern with 'uncertainty as the ordinary' is more fruitful than merely focusing on temporally limited shock events, as is often the focus in disaster studies.

The livelihoods approach suggests that individuals rely on different forms of capital (human, social, natural, physical, and financial) (Scoones 1998), which are applied towards social and personal well-being, and directed towards more 
sustainable life outcomes. These forms of capital and their strategies of application are influenced by vulnerabilities, which range from seasonal changes to short-term shocks and long-term trends. Simultaneously, they are embedded in and influence institutional and social structures and processes such as laws, policies, or government authorities (Bohle 2013). The livelihood framework illustrates the reciprocal influence of livelihood strategies, capitals at hand, vulnerabilities and social structures (Chambers and Conway 1991; Scoones 1998, 2015), all of which have an influence on and are also influenced by aspirations. People's livelihood strategies may go beyond merely 'hanging in' or coping with different situations, and include strategies for 'stepping up' in local economies, or 'stepping out' by drawing on linkages to distant markets in order to overcome poverty (Dorward et al. 2009). The combination of strategies is shaped by broad socio-economic contexts, assets, and skills, which include capabilities, resources, and opportunities to pursue different aims. Moreover, the strategies vary with personal circumstances, perceptions of opportunities, and constraints. When facing everyday uncertainties, people living in poverty tend to adopt hanging-in strategies, aspiring to maintain current livelihood sources and standards (Dorward 2009; Kamwi et al. 2018).

Unlike the more systematic approach of livelihood strategies, aspirations are usually ascribed to the individual, but portraying actors as guided by economic, cultural, and other contextual considerations, which renders aspiration unlike e.g. 'preferences' a collective activity (Appadurai 2004, p. 60; Bernard and Taffesse 2014; Besley 2017; Ray 2006, p. 409). Bernard and Taffesse (2014) portray aspirations as future-oriented sources of motivation, and as perceived ambitions toward multidimensional life outcomes. This suggests that aspirations are a suitable medium for studying the impact of actors' culturally, socially, as well as economically informed future-orientations on their livelihood decision-making strategies. To differentiate aspirations from 'hopes' or 'wishes', we follow Bernard and Taffesse (2014) and Bernard et al. (2011), who distinguish aspirations by a willingness to invest effort, time, money, and other resources toward reaching certain goals - to address tangible visions-even if willingness to make such investments remains "potential or conditional" (Bernard et al. 2011, p. 6). Furthermore, decision-making is shaped by individual desires, which are variously informed by their experiences and knowledge of immediate social and physical environment (Ray 2006). Scrutinising both internal and external influences sheds light on individual and household agency and contribute better understanding of the structural implications on livelihood strategies-both individual and collective.

According to Ray (2006, p. 410), aspirations are created out of the "lives, achievements, or ideals of those who exist in [an individuals'] 'aspirations window'". In terms of how aspirations are formed, this suggests that they are shaped socially, "formed from an individual's cognitive world, her zone of 'similar,' 'attainable' individuals" (Ibid.). Social learning, by observing others' experiences, is a safe way to deal with everyday uncertainties and to inform one's decisions. Ray's (2006) concept of an 'aspirations gap' helps to understand the scope of aspirations toward which individuals and groups work, from high aims to lowscale plans. Given the costs involved in moving from one standard of living to an aspired one, the gap cannot be too broad nor too narrow. If too wide, an aspiration 
may not be attainable, leading to frustration or 'fatalism' (Bernard et al. 2011). In contrast, aspiration gaps that are too narrow reduce the reward involved in the effort of attaining one's goal.

As much as aspirations are influenced externally by the social environment, they are shaped by internal cognitive processes, such as propensity for risk-taking, perception, and judgement, which are complex psychological and individual attributes that go beyond the scope of this paper (Lybbert and Wydick 2018). With respect to learning and experiences, the concept of 'locus of control' helps us to understand the impact that experience can have on aspirations (Bernard et al. 2011). Here, the individual locus of control is the perception of the extent to which one can influence occurrences internally or to what degree events are beyond one's control. (Ibid.).

In his book chapter, 'The Capacity to Aspire', Appadurai seeks to "strengthen the idea of aspiration as a cultural capacity" (2004, p. 62), using the term to describe cultural orientations toward the future. According to Appadurai, cultural capacities are collective capacities. To study aspirations thus means that one must step back to consider how collective horizons are shaped. Yet, any sort of consensus cannot be taken for granted, as aspirations are negotiated through verbal and material rituals and 'performances' (Appadurai 2004). While we do not provide longitudinal details on socially negotiated aspirations, we point out that individual ideas about the future frequently reflect social norms and-when voicedsuch norms are frequently contested and subject to reinterpretation.

In our contribution, we highlight 'uncertainty' and long-term imponderability, which form the background of aspirations and livelihood strategies. Uncertainty is a state where conditions are not already known, and competing outcomes may be variously possible or impossible (Pine 2019). In particular, uncertainty highlights situations when "something of value is at stake.... [Uncertainty] can relate both to the chances of a negative outcome and the nature of the outcome itself" (Boholm 2003, p. 166). Uncertainty shifts the focus from rational choice making in situations of risk to the culturally and socially embedded individual (Boholm 2003). Thus, one is able to link external or structural constraints from an individual's perspective, which simultaneously have internal effects. Particularly in rural areas with high poverty rates, such uncertainties lie at the core of people's everyday lives. Pine (2019, n.p.) points out that "living with uncertainty as a part of their ordinary, people evoke particular pasts, and imagine various futures, in order to manage the present".

Drawing together perspectives on aspiration, uncertainty and sustainable livelihoods allows us to look beyond access to and use of capital and other assets for expanding economic possibilities, but also considers implications of people's social and cultural embeddedness for their agency and future-oriented economic decisionmaking. We trace aspirations to explore visions of the future from various individual and collective contexts. Focusing on uncertainties rather than vulnerabilities permits us to stress perceptions of the economic, natural, and social environment by the actors themselves. Moreover, in contexts where uncertainty as the ordinary influences every aspect of daily life, consideration of tangible or realisable opportunities may be hampered. 


\section{Methodology}

\section{Research Area}

The study is based on qualitative data collection in July 2019 across the Zambezi region, which is an area $14.785 \mathrm{~km}^{2}$ in size. Its administrative urban centre, Katima Mulilo, sits on Namibia's border with Zambia. The climate is tropical, with a hot rainy season during the summer, from December until March, and a dry season during winter months. Encompassed by the Kwando and Linyanti/ Chobe Rivers, Zambezi's diverse terrain is comprised of swamps, floodplains, wetlands, woodlands, and grasslands (Kangumu 2011; Namibia Statistics Agency 2017a).

With a population of 98,849 in 2016 , and a population density of 6.7 persons per $\mathrm{km}^{2}$, most people in the region live from a mix of part-time employment, agricultural income, and the seasonal sale of fish, reeds, and grass bundles (Kamwi et al. 2018; Namibia Statistics Agency 2017a). As reported in the 2016 Namibia Labour Force Survey, $45 \%$ of households reported 'salaries and/or wages' as their main source of income (Namibia Statistics Agency 2017b). Income generated from these activities is generally low and irregular. The diversification of local economic activities is further influenced by the seasonality of crops, periodic floods and droughts, and low human capital owed to limited education and training (Kamwi et al. 2018). Some $48 \%$ of Zambezi's population was unemployed in 2016 compared to the national unemployment rate of 34\% (Namibia Statistics Agency 2017b), and as mentioned in the introduction, calculations by the World Bank, based on the Namibian Household Income and Expenditure Survey from 2009 , indicate for 2019 an absolute poverty rate of $17.6 \%$, which amounts to surviving on less than US\$1.90 per day (World Bank 2020).

We conducted research in eight settlements of different sizes consisting of various nuclear families each housed in their own courtyard. Several courtyards formed by extended families constitute a small village, and a collection of these small villages form a settlement. Traditional Authorities (TA) comprising of Indunas (local tribal chiefs) are responsible for mediating social and legal issues among settlement residents. Especially the distribution of land for settlement or for cultivation can be jointly discussed by the parties concerned, but such matters are ultimately decided by Indunas. Other matters are negotiated within the family. Apart from this, a village development committee, which (ideally) consists of members from different extended families, makes decisions about developmental issues. As these sketches of settlement structure are schematic, we also found complex variations that occurred within and between settlements. Delimiting settlement boundaries can thus be quite complicated for non-intimates, but working distinctions are necessary when studying communal economic projects. 


\section{Methods and Data}

The research was undertaken in July 2019 through a joint field study by Namibian and German students and scholars. In this article, we mainly rely on data from eight focus group discussions (FGD), seven individual interviews, and one goalong interview with a particular focus on aspirations (see Table 1).

FGDs primarily offered quick access to the field and an opportunity to simultaneously address and contrast individual and communal scales. Following Hennink (2014), a semi-structured discussion guideline was focused on various livelihood strategies, both collective and individual aspirations, as well as motivation and implementation. The groups consisted of 5 to 25 mixed gender adults (over 18) who were selected by the respective Indunas, whereas our interest was that participants were involved in settlement development. Our discussions sought to contrast different degrees of involvement in settlement life in order to encourage discourse on different ideas and approaches to development and livelihoods. Questions were posed in English and a local language (e.g., Silozi, Chisubia, and Sifwe) by the Namibian scholars and students participating in this field study, and responses were translated in real-time. We requested (and were granted) verbal permission to use recordings and other documentation, and we guaranteed anonymity by using coded references for person and place names.

To deepen our understanding of the broad and multidimensional topic of aspiration, comprising collective as well as individual concerns, we used a semistructured qualitative interview protocol in one-on-one interviews. While the interview guidelines helped to establish some degree of comparability, the open nature of this interviewing method allowed for spontaneous, in-depth followup questions (Schlehe 2008). Additionally, during our go-along interview, we accompanied one farmer on a long walk around his land and village. We dialogued with him about his personal experiences, aspirations, and motivations, as they related to different aspects of the surrounding environment. By accompanying interlocutors into the various settings of their everyday lives, researchers are able to capture "the stream of perceptions, emotions, and interpretations that informants usually keep to themselves" (Kusenbach 2003, p. 464).

'Aspiration' is not a term that is frequently found in everyday usage, and the academic definition given in the introduction is anything but intuitive. Since there is no

Table 1 Qualitative data collection

\begin{tabular}{llll}
\hline & Focus group discussion & Interview & $\begin{array}{r}\text { Go-along } \\
\text { interview }\end{array}$ \\
\hline Village 1 & & I-7 & \\
Village 2 & FGD8 & & \\
Village 3 & FGD7 & I-6, I-3 & \\
Village 4 & FGD5, FGD6 & I-1 & I-9 \\
Village 5 & FGD4 & I-4 and I-5, I-2, I-8 & \\
Village 6 & FGD3 & & \\
Village 7 & FGD2 & & \\
Village 8 & FGD1 & & \\
\hline
\end{tabular}


direct translation into local languages, we used the Silozi term mulelo, which translates as 'aim'. This is quite contrary to the term 'hope', which can be directly translated into the Silozi word sepo. Instead of offering an abstract and academic definition of aspiration, we hoped that this term would encourage participants to recount their personal understandings of their future. Furthermore, to distinguish tangible aspirations or aims from less tangible dreams, wishes, visions, and hopes, in our analysis we focused on central criteria such as the willingness to invest resources (e.g., time, effort, money) in a future-oriented aim (Bernard and Taffesse 2014, p. 199). Therefore, in both focus group discussions and individual interviews, we asked about concrete plans and general willingness to engage in different kinds of investments. We applied deductive as well as inductive categories in coding responses (Mayring 2010). We used ethnographic vignettes from the protocols, as well as anonymised quotes from interviews, to illustrate and develop arguments beyond the theoretical framing (Plows 2008).

The relatively short 2-week period of fieldwork did not allow us to deepen our understanding of people's motivations or the contexts shaping their lives through follow-up interviews and other research activities. We were also unable to include perspectives from various developmental institutions, whether NGOs or governmental agencies. The following analysis, however, highlights different ways that heterogeneous aspirations are formed by individuals and among diverse communities. We do not attempt quantification or generalisation from the results of this study.

\section{Empirical Analysis and Discussion}

This section discusses the formation of aspirations against the backdrop of 'uncertainty as the ordinary' in the Zambezi context. We begin by analysing the aims, motivations, and goals that informed our interlocutors' aspirations, first focusing on the individual level and then at a collective level. We argue that persistent uncertainties experienced in everyday life can have a significant influence on livelihood decisions-even more than temporary shocks, as is frequently suggested by the sustainable livelihoods' framework. Aspirations are formed against this backdrop of uncertainty and informed by examples from everyday media consumption or personal experience. We argue that the diverse aims we encountered, and the heterogeneous images of the future presented in 'communities', are not accounted for in development programs that assume broad-based cooperation.

\section{Individual Aspirations}

Livelihood strategies in the Zambezi region often consist of seasonal or intermittent and heavy labour, for instance grass cutting, piecework, collecting firewood, or (subsistence) farming. Agricultural and pastoral activities such as cultivating maize or keeping cattle are highly dependent on the steady availability of, and access to, water; as the 2019 drought showed, these activities do not constitute a reliable livelihood source. Subsistence farmers indicated they had no money or access to loans to 
invest in productive activities, for example, to install irrigation, to build local processing facilities, to strengthen the local circulation of goods and money, or to facilitate access to goods among local populations. Furthermore, government payments, such as subsidies for registered kindergartens, are very unreliable (I-1, I-2). When this is the case, local families must rely on their own limited savings, odd jobs, as well as support from the parents of the kindergarten children, which was more reliable for research participant I-2 and less so for I- $1 .{ }^{1}$ Almost all interlocutors mention this unreliability as the biggest constraint, and it is nearly impossible for most people in the area to accumulate savings. Furthermore, access to training and education are limited by financial constraints or lack of knowledge about existing training programs (I-1, I-3, I-4 and I-5, I-6). For many daily needs such as school materials, clothing or food, having money is a precondition that is often lacking for people who depend at least partially on subsistence farming (I-2, FGD4, FGD1). Furthermore, the Zambezi region has one of the highest youth unemployment rates in Namibia, affecting skilled and unskilled, educated and uneducated. This has created a situation where household income depends highly on state subsidies such as drought relief or the highly valued pension programs for elderly people. Almost all of our interlocutors described these factors as shaping everyday uncertainties in their abilities to fulfil basic everyday needs.

One elderly woman (I-3), who was head of a household of 10, cultivates land for subsistence farming. The only income-generating activity she does is cutting grass, which is highly dependent on rainfall and restricted to the months of May to July. When we asked what other activities she sees herself potentially doing in the future, if she had the means to do so, she mentioned opening a small shop to generate a steadier flow of income. This example shows that one of the most pressing issues is more regular income, which would help reduce uncertainties and irregular access to consumer goods. This woman's aspiration may have been influenced by another woman from her village, one of our interlocutors (I-6), who had just opened a small shop in this village and was the only visible example of a local business.

The necessity to earn and eventually save money can also hamper the development of dreams into aspirations, as one young man (I-7) illustrated: Realising that there are many talented musicians among his friends, he expresses a desire "to have maybe a studio, a music studio. It's a dream". However, he also stated that he neither had the capital nor the skills necessary to realise the dream. This did not mean that he would give up on the idea, but, for now, "something that works" for him is only achievable through manual labour. Here, the aspirations gap (Ray 2006) is too broad for the interviewee: turning his dream into reality involves costs that are too high, or not perceived as feasible, so that an actual aspiration cannot develop from what remains a dream.

\footnotetext{
1 By chance, two of the eight interview partners were kindergarten teachers. The women were interested in child rearing (I-2) or early childhood education (I-1) even before the decision to open a kindergarten was made, and both were inspired to realise this goal by an external influence. Compared to other kinds of activities, establishing a kindergarten does not require a large financial investment due to free training courses and has low formal preconditions. One major difficulty is to obtain consent for opening a kindergarten from the Indunas.
} 
These excerpts from our interviews demonstrate that external market and environmental constraints translate into everyday uncertainties for individuals and illustrate various strategies for dealing with them across different levels of education and degrees of economic diversification. In this context of uncertainty, others form ideas and strategies about the future that are instead perceived as feasible. Thus, for many of our interlocutors, the idea of a 'good life' involves a life in which those uncertainties are mitigated or do not exist, for example, when they can easily afford to educate their children or fulfil necessary family needs with ease (I-1, I-3, I-4, I-5, I-6, I-7). Two people described their vision of a good life in the following manner:

My own house, my own family, I put food on the table, I prepare everything for my family, take them to school. That is a good life (I-7).

A good life is having something which makes your life easier. That is a good life, instead of suffering! Doing tough labour like cutting grass or selling traditional fruits - every day you have to walk to the forest and find traditional fruits to sell - that is not a good life (I-1).

We consider these expressions of good life as motivating aims, shaping personal ideas about the future that are shot through with social and cultural meanings.

Several studies suggest that role models can be inspirational, and that imitating and learning from them may affect one's aspiration. Ray (2006, p. 410), for example, observes that aspirations are shaped by 'attainable individuals' identifiable from within one's social environment. For example, a study by Beaman et al. (2012) investigated the effect that female leaders in village councils have on adolescent girls' career aspirations and educational attainment. They suggest that the girls' (and their parents') aspirations change through two channels: either by transforming the general conditions for girls to succeed, for example through government policies that change "beliefs on what is possible for girls" (Beaman et al. 2012, p. 584), or by presenting a role model of a successful woman. Furthermore, Bernard and Taffesse (2014, p. 193) suggest that "positive attitudes towards the future may indeed be contagious, in that witnessing local success stories of upward mobility can change other individuals' investment behaviour".

Inspiration from other people or other external sources was key to our interlocutors, as many told us about examples of others near them who inspired them. One woman (I-2) explained that while she was transporting fish from the river to her village, she met a woman who was running a kindergarten by herself. Even though the woman did not earn money by taking care of the children, as she explained to us, the woman did not mind as it was her passion. She wanted to "copy this woman's strategy," but to register with the Ministry of Gender Equality and Child Welfare in order to generate income. Furthermore, she finds this kind of work rewarding because she loves spending time with children. Two other interview partners (I-4 and I-6) learned the skills necessary for their current and future livelihood strategies from family members - an uncle taught one of two prospective carpenters (I-4) how to work with wood, while the mother of the shop owner (I-6) cited above gave her sweets to sell to her secondary school classmates.

Popular media is also a source of inspiration for some of the people we interviewed (I-5 and I-1): YouTube videos of successful businessmen led one young man 
(I-5) to plan a carpentry business, which he sought to build with a friend (I-4). It is not only positive future outcomes that motivate people to reach certain aims. Cautionary examples can also motivate people to aspire for more, as related by one of our interview partners (I-1). The effort she put into successfully opening a kindergarten was due to fears of "doing nothing," as she explained: "Like a lot of people in the settlement, many who get education end up unmotivated, not doing anything [...]". Her personal failures also had an impact on her aspiration to be a kindergarten teacher. After failing to complete her secondary education, she wanted to stay active and not forget everything she learned. She thus resolved to open her own kindergarten, having been inspired by a radio show about early childhood education. Here again, many facets and processes contributed to the development of her aspirations: initial failure and dissatisfaction, both personally as well as negative examples from the 'outside', including others' life outcomes, led to a strong motivation to change something in her life. This resulted in the formation of a plan that she worked toward, and eventually succeeded in realising, while still having future aspirations to expand and modernise the kindergarten. This in turn was motivated by her passion for teaching and a need for stability.

Together, the wishes and aims addressed in the interviews disclose a range of underlying motivations, which are shaped by individual preferences and beliefs, social motivation like family and friends and-when referring to future-oriented behavior-expectations and aspirations. The example of another woman who founded a kindergarten (I-1) illustrates the difference between wishes and aspirations: she is planning to build a permanent structure for her kindergarten so she would not have to remain outside with the children in her care. To realise this plan, she is trying to save money to buy the necessary construction materials. Saving money adds to more certainty to her business and contributes to her overall plan to expand the kindergarten, realising her personal passion for early childhood education. This woman's case exemplifies the future-oriented, multi-dimensional, and motivational aspects involved in the capacity to aspire.

During another interview, one young man (I-9) described extensive aspirations: after living and working in Windhoek as a security guard, he returned to his childhood settlement where he started a horticulture garden with the goal of transforming it into a community garden. He invested significant time and work in his project, for example, travelling as far as Zambia to buy the right tomato seeds and to learn more about cultivation. During our research, he was still trying to determine what cultivars worked best and he even employed other community members to help water the plants. Becoming acquainted with a variety of people, living standards, business opportunities, and other ideas in Namibia's capital, and afterwards putting his plans into action, indicates that those encounters and experiences shaped his aspirations.

For most of our other interviewees, who were confronted with very limited opportunities or work possibilities in the settlements, many of their aspirations were focused on the improvement or extension of existing circumstances. This indicates that their aspirations do not include ideas and ambitions outside of their respective window and were often primarily concerned with reducing everyday uncertainties that are prevalent in contexts of poverty. To further summarise the formation of aspirations discussed above, additional reasons and motivations to aspire toward a 
future-oriented goal can be traced to a range of capabilities, experiences, and possibilities. Personal experiences, inspirations, and role models in one's cognitive window, combined with various internal factors like personality traits, judgement, awareness, among many others, are determinants that shape aspirations (Bandura 1977; Ray 2006).

\section{Collective Aspirations}

How are collective aspirations shaped as a cultural capacity, according to Appadurai? In what follows, we address the notion of a collective 'capacity to aspire' (Appadurai 2004).

Some of the villages where our study was conducted are part of a communal conservancy, derived from a policy that proposes to distribute economic benefits from nature conservation in order to benefit people living in conservancies. This policy suggests that mechanisms for 'communal' economic decision-making should be in place, which should in turn shape collective aspirations. This observation encouraged us to ask questions about 'projects in the community' and 'aims of the community,' despite many studies that have shown that a singular 'village community' is typically a reification of rural life. They suggest that the idea of community is more complex than mere kinship or geographical location (e.g. Brint 2001; Crow and Allan 1994; Strathern 1981). As Lange shows in the case of Egypt using the term 'strategic tribalism', the Tahawi Bedouins employ such a narrative of the coherent community as a form of place- and claim-making (Lange 2021).

For those who participated in interviews and focus groups, the issues of "projects in the community" and "aims of the community" were constantly raised. The researchers presented a hypothetical scenario in which a settlement would unconditionally receive Nam\$ 1.5 million (equals roughly 80.000 Euros) and asked how the community would use the money. This scenario sparked both vivid and protracted discussions (FGD4), or, in some cases, only short responses were given. Answers ranged from a community bakery or a community garden to opening a butcher shop, helping orphans, or buying cattle and then splitting them among households. Other ideas concerned infrastructural projects such as drilling boreholes or electricity provision (FGD1, 2, 4, 5). Beyond infrastructural projects, the desire for stable employment was mentioned several times, such as through a green scheme project or the creation of campsites near conservancies (FGD1). As with individual aspirations, the reasons given in support of these ideas addressed long-term socio-ecological uncertainties, such as insecure availability of water, bush fires, crop damage caused by wild animals, or general economic insecurity given the few employment opportunities and limited agricultural production (FGD1, 6).

When researchers asked whether any similar project was implemented in the past, we received almost no responses. In the settlement where the bakery project was mentioned, the specific requirement of the lead NGO's funding programme is that five people must jointly apply (FGD5). The problem in this community was that there was no working trust among the people in the community, which made cooperation a personal risk for fear of corruption, should the application be successful. 
Nevertheless, when trust is not an issue, alliances for joint projects can be successful. Two friends (I-4, I-5) tried to pool their small savings together to buy the necessary machinery to start a carpentry business, although they will need additional funding in the long run. Both point out that once they are successful, other people in the settlement will profit, as they would have employees and be able to support orphans and widows with monetary surpluses.

The young man (I-9, see Sect. 4.1) who sought to develop a community garden after returning from Windhoek illustrates another difficulty in working collectively toward common goals. His initial plan was to use his savings as capital to build a community garden on local land. He was willing to invest the money, but, as he states, "the others didn't want to volunteer", and just watched while he was working. Frustrated, he continues with his plans by himself, temporarily employing people to help with tasks such as watering the fields. His first aim is to sell produce locally. Although he now oversees the project alone, he states several times that the local settlement residents will be among the first to benefit, both from possible employment and by no longer needing to travel to town to buy fresh produce.

Thus far, we have either encountered aspirations to create employment or to reduce the uncertainties of agricultural production. On the other hand, developing tangible plans from dreams, and working toward a common goal, involved various degrees of cooperation.

The discussions and disagreements we described above suggest that there is a generational shift in terms of preferred economic activities. In FGD5, elder men dominated discussions about possible communal projects. Their suggestions mainly revolved around agriculture projects and infrastructure improvements, such as butcheries, to better market and monetise their cattle. One young focus group participant, who had mentioned several projects apart from agriculture, remarked after the discussion: "Those old men only think about their water and their cattle." In FGD4, the discussion about what to do with a hypothetical project budget of Nam\$ 1.5 million lasted about $15 \mathrm{~min}$ and even got quite heated. While nearly all of the 15 participants proposed and defended ideas of their own, it eventually became clear that the focus group was divided in two groups: younger participants agreed to vote for a non-agricultural project that would be economically beneficial and generate surplus that could be reinvested in infrastructure or social projects. Older participants opted for agricultural projects, arguing that they had to build on existing knowledge and resources, but also keeping in mind settlement residents who could not take care of themselves. The compromise proposal by a younger participant was to invest in a project that would provide steady water access to everyone, which would serve as an infrastructural requirement for both kinds of proposed projects. The older participants voiced understanding for the younger participants, as well. One woman in particular suggested that while she had learned how to work cutting grass and poles, younger people need new competences and ways to make a living. In a follow-up interview, a 60-year-old man (I-8) explains that he wanted to become a teacher when he was younger, but back in those days, people believed that agriculture was the future for his generation. However, he lacked support and guidance on how to achieve his plans. He also states: "It will be very hard for them to do what I am doing to make a living today, as times are changing". While in some places, 
there was disagreement about what was to be done, in other places there was greater understanding for different positions. Overall, different generations have clearly contrasting economic visions.

These different ethnographic snapshots and interview excerpts help us to visualise different arguments. First, in our study, there was not a single community that made economic decisions collectively. Economic decision-making was rather done through different alliances_-from families to friends_- which are rather small. Discussions regarding past community projects revealed that there have not been many successful projects except in one village (FGD2). Secondly, people suggest and attempt collective projects, but they are far from being consensual. On the one hand, this is because of opposed interests, as Hulke et al. (2020) show in the case of communal conservancies: top-down policies imply that benefits are evenly distributed among 'communities', but in practice some groups do not profit. Farmers, for example, feel they lack involvement or sufficient information, and that their aims may be contrary to conservation. On the other hand, our interlocutors pointed out that generational aspirations differ: older people tend to rely on their experience with agriculture, while younger people see themselves building livelihoods beyond agricultural production. These generational differences make it difficult to establish "collective horizons," which are, following Appadurai, the basis for "collective aspirations" (2004, p. 61).

\section{Conclusion and Implications}

Livelihood choices and strategies in the Zambezi region are made against a backdrop of everyday uncertainties, which are experienced by people with different occupations and levels of education. The greatest livelihoods uncertainties expressed by our interlocutors were due to external market and environmental constraints, which translate into everyday uncertainties such as little money, limited opportunities to accumulate assets or savings, lack of regular income from steady employment, or crop losses due to drought or wildlife damage. Ideas and strategies for bringing about different futures are formed in this context of uncertainty. The focus on aspirations offers a perspective for investigating why some people creatively explore new strategies, while others seek to merely 'hang in'.

Individual aspirations cannot be detached from their social embeddedness, suggesting that individual experiences (or internal cognitive processes) are not the only influences on future-oriented decision-making, but that the experiences of and relationships with other people also shape individual aspirations, either positively or negatively. Our qualitative data suggests that aspirations generally take into account several dimensions of well-being. The cognitive window for people's diverse aspirations builds on negative and positive examples and role models from their immediate environment, as well as inspiration from people and examples in media. However, when the 'aspiration gap' is too wide, costs are too high, and plans appear to be non-feasible, dreams do not develop into aspirations.

When investigating the 'collective capacity to aspire', it is apparent that people's ideas about the 'good life' also concern people around them. However, as 
several funding schemes demanded that communities build a collective voice and vision for their future, we found that such collective articulation is difficult, as most economic decision-making occurs in smaller scales. Thus, joint orientations and collective efforts toward future economic outcomes cannot be taken for granted by merely invoking imagined communities, such as villages or settlements. The suggestion for building a collective 'capacity to aspire', and to close the 'aspirations gap', is thus to provide people with the means to realise these kinds of undertakings, to provide easier financial support for those with ideas for individual projects, and to provide necessary examples to shape collective horizons.

Translated into policy implications for regional development, (non-)governmental actors must consider that access to information, the role of experience, and perceptions of possibilities are crucial for livelihood choices, especially in poverty contexts. We first conclude that when considering projects such as kindergartens, it is central to extend free training opportunities and to communicate better about existing ones. Second, new ideas and local role models can contribute to empowerment and decision-making about livelihoods. Therefore, training, accessibility, and affordability are decisive. However, it is important to consider opportunities for nonformal learning, as inspiration is found in examples from everyday and immediate surroundings. Thus, options for local exchange and mentoring must be enhanced to support capacity building. Furthermore, both individual and cooperative rural development projects have to be promoted and encouraged, and funding options for individual projects should be advanced. To achieve this, different sociocultural patterns also need to be recognised in the region, as these are key to realising aspirations. In order for sustainable collective aspirations to be voiced, however, bottom-up processes need to be supported through which community members can identify and negotiate common necessities relevant to their diverse projects.

In this contribution, we defined aspirations in terms of motivating factors for investing resources within wider livelihood strategies. Our research participants elaborated aspirations that built on their experiences and immediate needs for the future. Yet, defining aspirations in this way also limits the findings of this study. By excluding dreams, visions, or spontaneous ideas from our analysis, as they are not being actively pursued as motivators, our study also foreclosed discussion of broader group visions or alternative development pathways beyond individual projects. Yet, larger visions that take into account the plurality of imaginable forms of cooperation and collaboration are necessary to access local ideas about futures beyond 'feasible' paths of individual livelihoods. Opening space for dreams would "fundamentally shift the geography and biography of knowledge" (Ndlovu-Gatsheni 2019 , p. 46). That is why the term mulelo or 'aim' (see Sect. 3.2), which is found in everyday language, may give rise to new development narratives beyond those that exclusively inquire into the feasibility of development projects for individuals.

Funding Open Access funding enabled and organized by Projekt DEAL. 


\section{Declarations}

\section{Conflict of interest None.}

Open Access This article is licensed under a Creative Commons Attribution 4.0 International License, which permits use, sharing, adaptation, distribution and reproduction in any medium or format, as long as you give appropriate credit to the original author(s) and the source, provide a link to the Creative Commons licence, and indicate if changes were made. The images or other third party material in this article are included in the article's Creative Commons licence, unless indicated otherwise in a credit line to the material. If material is not included in the article's Creative Commons licence and your intended use is not permitted by statutory regulation or exceeds the permitted use, you will need to obtain permission directly from the copyright holder. To view a copy of this licence, visit http://creativecommons.org/licen ses/by/4.0/.

\section{References}

Appadurai, A. 2004. The Capacity to Aspire: Culture and the Terms of Recognition. In Culture and Public Action, ed. V. Rao and M. Walton, 59-84. Stanford: Stanford University Press.

Appadurai, A. 2013. The Future as Cultural Fact: Essays on the Global Condition. London: Verso.

Bandak, A., and M.K. Janeja. 2018. Introduction: Worth the Wait. In Ethnographies of Waiting: Doubt, Hope and Uncertainty, ed. M.K. Janeja and A. Bandak, 1-41. London: Bloomsbury Publishing Plc.

Bandura, A. 1977. Self-Efficacy: Toward a Unifying Theory of Behavioral Change. Psychological Review 84: 191-215.

Beaman, L., E. Duflo, R. Pande, and P. Topalova. 2012. Female Leadership Raises Aspirations and Educational Attainment for Girls: A Policy Experiment in India. Science (New York, NY) 335: 582-586.

Bernard, T., S. Dercon, and A.S. Taffesse. 2011. Beyond Fatalism: An Empirical Exploration of SelfEfficacy and Aspirations Failure in Ethiopia. IFPRI Discussion Paper. International Food Policy Research Institute.

Bernard, T., and A.S. Taffesse. 2014. Aspirations: An Approach to Measurement with Validation Using Ethiopian Data. Journal of African Economies 23: 189-224.

Besley, T. 2017. Aspirations and the Political Economy of Inequality. Oxford Economic Papers 69: 1-35.

Bohle, H.-G. 2013. Vom Raum zum Menschen: Geographische Entwicklungsforschung als Handlungswissenschaft. In Geographie, ed. H. Gebhardt, R. Glaser, U. Radtke, and P. Reuber, 746-763. Heidelberg: Spektrum.

Boholm, A. 2003. The Cultural Nature of Risk: Can There Be an Anthropology of Uncertainty? Ethnos 68: $159-178$

Brint, S. 2001. Gemeinschaft Revisited: A Critique and Reconstruction of the Community Concept. Sociological Theory 19: 1-23.

Chambers, R., and G.R. Conway. 1991. Sustainable Rural Livelihoods: Practical Concepts for the 21st Century. IDS Discussion Paper 296.

Crow, G., and G. Allan. 1994. Community Life: An Introduction to Local Social Relations. London: Routledge.

Dalton, P.S., S. Ghosal, and A. Mani. 2015. Poverty and Aspirations Failure. The Economic Journal 126: $165-188$.

Dorward, A. 2009. Integrating Contested Aspirations, Processes and Policy: Development as Hanging In, Stepping Up and Stepping Out. Development Policy Review 27: 131-146.

Dorward, A., S. Anderson, Y.N. Bernal, E.S. Vera, J. Rushton, J. Pattison, and R. Paz. 2009. Hanging in, Stepping Up and Stepping Out: Livelihood Aspirations and Strategies of the Poor. Development in Practice 19: 240-247.

Hennink, M.M. 2014. Understanding Focus Group Discussions. New York: Oxford University Press.

Hulke, C., J.K. Kairu, and J.R. Diez. 2020. Development Visions, Livelihood Realities-How Conservation Shapes Agricultural Value Chains in the Zambezi Region, Namibia. Development Southern Africa 38 (1): 1-18.

Iqani, M. 2017. Consumption, Media and Culture in South Africa. London: Routledge. 
Kamwi, J.M., P.W.C. Chirwa, F.P. Graz, S.O.M. Manda, A.W. Mosimane, and C. Kätsch. 2018. Livelihood Activities and Skills in Rural Areas of the Zambezi Region, Namibia: Implications for Policy and Poverty Reduction. African Journal of Food, Agriculture, Nutrition and Development 18: 13074-13094.

Kangumu, B. 2011. Contesting Caprivi: A History of Colonial Isolation and Regional Nationalism in Namibia. Basel: Basler Afrika Bibliographien Namibia Resource Center and Southern Africa Library.

Kusenbach, M. 2003. Street Phenomenology: The Go-Along as Ethnographic Research Tool. Ethnography 4: 455-485.

Lange, C. 2021. How to Win Elections in the Eastern Delta of Egypt: Towards the Idea of a Strategic Tribalism. Special Issue: Rethinking the Mediterranean. Zeitschrift für Ethnologie 145: 1-26.

Lybbert, T.J., and B. Wydick. 2018. Poverty, Aspirations, and the Economics of Hope. Economic Development and Cultural Change 66: 709-753.

Mayring, P. 2010. Qualitative Inhaltsanalyse. In Handbuch Qualitative Forschung in der Psychologie, ed. G. Mey and K. Mruck, 601-613. Wiesbaden: VS Verlag für Sozialwissenschaften.

Mosimane, A., S. Lendelvo, S. Glatz-Jorde, H. Kirchmeir, and M. Huber. 2014. Livelihood Baseline Survey Report for the Kavango Zambezi Transfrontier Conservation Area (KAZA TFCA).

Mpofu, B., and S.J. Ndlovu-Gatsheni. 2019. Rethinking and Unthinking Development in Africa. In Rethinking and Unthinking Development: Perspectives on Inequality and Poverty in South Africa and Zimbabwe, ed. B. Mpofu and S.J. Ndlovu-Gatsheni. New York: Berghahn Books.

Namibia Statistics Agency. 2017a. Namibia Inter-censal Demographic Survey 2016 Report.

Namibia Statistics Agency. 2017b. The Namibia Labour Force Survey 2016 Report. Namibia Statistics Agency.

Ndlovu-Gatsheni, S.J. 2019. Rethinking Development in the Age of Global Coloniality. In Rethinking and Unthinking Development: Perspectives on Inequality and Poverty in South Africa and Zimbabwe, ed. B. Mpofu and S.J. Ndlovu-Gatsheni. New York: Berghahn Books.

Pine, F. 2019. Ordinary Uncertainties: Remembering the Past and Imagining the Future at Times of Rupture and Mobility. In Paper Presented at the Conference "Rurality and Future-Making. Comparative Perspectives from Europe, the Middle East, and the Mediterranean”, 22-24 May, Cologne, Germany.

Plows, A. 2008. Social Movements and Ethnographic Methodologies: An Analysis Using Case Study Examples. Sociology Compass 2: 1523-1538.

Ray, D. 2006. Aspirations, Poverty, and Economic Change. In Understanding Poverty, ed. A.V. Banerjee, R. Bénabou, and D. Mookherjee, 409-421. New York: Oxford University Press.

Republic of Namibia. 2017. Namibia's 5th National Development Plan (NDP5).

Rostow, W.W. 1960. The Stages of Economic Growth, a Non-Communist Manifesto. Cambridge: Cambridge University Press.

Schlehe, J. 2008. Formen qualitativer ethnographischer Interviews. In Methoden ethnologischer Feldforschung, ed. B. Beer, 119-142.

Scoones, I. 1998. Sustainable Rural Livelihoods: A Framework for Analysis. IDS Working Paper 72, $1-22$.

Scoones, I. 2015. Sustainable Livelihoods and Rural Development. Rugby: Practical Action Publishing.

Strathern, M. 1981. Kinship at the Core: An Anthropology of Elmdon, a Village in North-West Essex in the Nineteen-Sixties. Cambridge: Cambridge University Press.

World Bank. 2013. Africa's Pulse, October 2013: An Analysis of Issues Shaping Africa's Economic Future. Washington, DC: World Bank.

World Bank. 2020. Macro Poverty Outlook. Sub-Saharan Africa (English). Macro Poverty Outlook, October 20. World Bank Group.

Publisher's Note Springer Nature remains neutral with regard to jurisdictional claims in published maps and institutional affiliations. 


\section{Authors and Affiliations}

\section{Mascha Aring $^{1}$ (D) . Ole Reichardt ${ }^{2} \cdot$ Ewaldine Menjono Katjizeu $^{3}$. Brendan Luyanda ${ }^{4}$. Carolin Hulke}

Ole Reichardt

ole.reichardt@outlook.de

Ewaldine Menjono Katjizeu

ekatjizeu@unam.na

Brendan Luyanda

luyandabrendan@gmail.com

Carolin Hulke

carolin.hulke@uni-koeln.de

1 Institute of Geography, University of Cologne, Otto-Fischer-Str. 4, 50674 Cologne, Germany

2 Department of Social and Cultural Anthropology, Institute of Geography, University of Cologne, Otto-Fischer-Str. 4, 50674 Cologne, Germany

3 Department of Geography, History and Environment Studies, University of Namibia, 340 Mandume Ndemufayo Ave, Pionierspark, Private Bag 13301, Windhoek, Namibia

4 Department of Wildlife Management and Ecotourism, University of Namibia, Ngweze, P.O. BOX 1230, Katima Mulilo, Namibia

5 Institute of Geography, University of Cologne, Otto-Fischer-Straße 4, 50674 Cologne, Germany 